\title{
TOPOGRAFÍA Y RITUAL EN LA NECRÓPOLIS DE CÁDIZ
}

\section{TOPOGRAPHY AND RITUAL IN THE NECROPOLIS OF CADIZ}

\author{
por
}

\author{
RAMÓN CORZO SÁNCHEZ
}

RESUMEN La finalidad del artículo es establecer los fenómenos de evolución geográfica que condicionan la conservación de las necrópolis de Cádiz. Se compara el número de enterramientos conocido con los cálculos demográficos para valorar los datos de cada fase histórica y se propone una estimación de la densidad de enterramientos que es posible excavar aún. En el análisis de los tipos de tumbas se establecen los rasgos que corresponden a la evolución del ritual y se indican las características más personales que pueden definir a la cultura gaditana y diferenciarla de la de otras poblaciones cercanas.

ABSTRACT This paper describes the main geographic processes that afect the conservation of funerary remains in Cádiz. A comparison is made between the recorded number of burials and the demographic estimations for each historic period in order to carry out the number of burials likely to be found in the future. The main ritual features of the burials are also described with a diachronic perspective.

Los habitantes de las islas gaditanas hubieron de limitarse durante toda la antigüedad a un espacio físico muy reducido. El problema territorial, que sigue siendo hoy una preocupación prioritaria, debió llegar a ser agobiante en los últimos decenios anteriores a la Era cristiana; dice sobre ello Estrabón: "En un principio vivían en una ciudad muy pequeña; mas Bálbos el Gaditanós, que alcanzó los honores del triunfo, levantóles otra que llaman «nueva»; de ambas surgió Didyme, cuyo perímetro, aunque no pasa de veinte stadios, es lo suficientemente grande para no sentirse agobiada de espacio; efectivamente, en ella residen pocos, ya que la mayoría pasan en la mar gran parte del tiempo, o viven en la tierra firme frontera, y sobre todo en la vecina islita, porque ésta es fértil; tanto es así que, agradándoles el lugar, han hecho de la islita una como «antípolis» de Didyme; pero en proporción son pocos los que habitan en ella y en el arsenal que les ha construido Bálbos en la tierra firme frontera" (Geografía, III, 5, 3. Trad. de A. García y Bellido, 1945, p. 176). 
Los Balbos aprovecharon su buena posición política en el momento de organización del Imperio para impulsar a su ciudad con nuevas edificaciones; ésto debió iniciarse durante las guerras civiles, cuando Cicerón refería el retiro de Balbo el Menor a Cádiz, sin intervenir en los conflictos, con la expresión "at Balbus aedificat" (ad Att. 12, 2, 1); así se explica que pudiera estrenar en el nuevo teatro una obra autobiográfica en el año 43 a. C., y celebrar allí otros actos populares y las elecciones fraudulentas de las que se quejaba a Cicerón el cuestor Asinio Polión ( ad fam. 10, 32, 1). En este terreno, los Balbos parecen ser los primeros provinciales hispanos que ponen en práctica el evergetismo como sistema de promoción política.

La intensa obra de los Balbos no se limitó a la promoción de obras urbanas, sino que se extendió a la ordenación de las islas y parte del litoral inmediato, para transformar toda la Bahía en un emporio comercial muy distinto de la vieja metrópolis fenicia, hasta entonces cauce de los intercambios entre las costas atlánticas y el Mediterráneo oriental, ahora centro de la exportación del vino y el aceite andaluz a la propia Roma.

La identificación de las islas que componían el archipiélago gaditano es un asunto en el que se ha avanzado bastante en los últimos años (Corzo, 1980, 1983 y 1991); también se conoce la situación y estructura del teatro edificado por Balbo (Corzo, 1989,1), así como las vías de comunicación trazadas en época romana (Corzo-Toscano, 1992, Corzo, 1992); sin embargo, las necrópolis de la ciudad, que son las que suministran desde hace más de un siglo, casi toda la información arqueológica, carecen de un análisis topográfico detallado.

Considero que un problema actual de gran interés, es el de valorar los hallazgos funerarios en toda su extensión, para determinar su validez como indicio de la evolución cultural de la ciudad y como paralelo para otras poblaciones de su mismo ámbito histórico.

El papel de Cádiz en la colonización fenicia de Occidente, su relación con Cartago y el carácter de su cultura en época romana, se establecen, por regla general, a la luz de los restos funerarios, y parece conveniente, por ello, determinar cuál es nuestro nivel de conocimientos sobre este asunto, y que aplicación puede darse a los datos arqueológicos sobre la necrópolis gaditana.

\section{LA CONSERVACION DEL SOPORTE FISICO}

En el conjunto de los últimos estudios sobre la topografía gaditana (Corzo, 1991), se han establecido los condicionantes de la historia geológica reciente de las islas, que explican la destrucción casi completa de la ciudad y la conservación parcial de la necrópolis.

La estructura geológica primitiva corresponde a la afloración reciente de un frente de areniscas pliocénicas, que fue cortado y erosionado por las avenidas del Guadalete en el período diluvial, y que ha pasado a constituir una barrera ante la desembocadura del río, desde el cuaternario aluvial, de modo que la extensa bahía interior se va colmatando con los aportes de la corriente (Gávala, 1973).

La primitiva barrera litoral, se extendía, al menos, desde Chipiona hasta Trafalgar, y en ella produjo el Guadalete varios cortes, para alcanzar el Océano; la boca de mayor amplitud es la que se abre entre El Puerto de Santa María y Cádiz, al sur, mucho más estrecha y colmatada está la del Caño de SanctiPetri, y debajo del propio recinto histórico gaditano se encuentra el cauce perdido de un canal que aislaba en la parte norte el emplazamiento de la primitiva colonia fenicia: la isla de Juno o Aphodisias. En el interior de la Bahía, sobresale el emplazamiento de San Fernando, o Isla de León, la "antípolis" de Estrabón, en la que aparecen emergidos algunos estratos de Era Secundaria bajo la roca arenisca ostionera. 
La hidrodinámica de la Bahía de Cádiz es muy compleja y de gran variabilidad estacional; en ella no sólo influyen la fuerza de la corriente del Guadalete y la presión del oleaje ascendente de las mareas, sino también el sistema general de corrientes en todo el Golfo de Cádiz, por el que confluye hasta la Bahía el cauce principal de la salida del Guadalquivir. De otra parte está el comportamiento de los temporales desde otoño hasta primavera y la colaboración o contrarresto a todas estas fuerzas que puede desarrollar el viento de Levante (MAPA, 1985 y 1989).

El comportamiento básico de estos fenómenos en sus manifestaciones de mayor actividad transformadora puede sintetizarse en la siguiente enumeración:

- El Guadalete aporta en los periodos invernales y primaverales un volumen muy considerable de aluviones, que corresponden a la erosión y arrastre de una cuenca muy extensa y de fuerte pendiente. Esta cuenca representa casi toda la extensión de la provincia de Cádiz, mas algo de la provincia de Sevilla, con un perfil que desciende más de mil quinientos metros en unos cien kilómetros de recorrido. En otros periodos históricos la composición de los aluviones sería esencialmente de productos naturales erosionados de las orillas; hoy, debido a las numerosas presas y a la conexión de los desagües urbanos e industriales, el aporte es más regular durante todo el año y está formado por residuos muy variados que provocan una turbulencia permanente con gran cantidad de materia orgánica en suspensión.

- Las mareas son de intensidad oceánica, con puntas de mayor coeficiente en los equinocios. La existencia de dos bocas de entrada a la Bahía (el canal principal entre El Puerto de Santa María y Cádiz y el Caño de Sancti-Petri), provoca una diferencia de hasta dos horas en la penetración de la pleamar por cada boca, con las consiguientes consecuencias de retención de los aluviones y agitación en los puntos de choque.

- Las corrientes marinas del litoral del Golfo de Cádiz, desde la Barra de Sanlúcar de Barrameda hasta la Bahía, provocan que una parte muy considerable de los arrastres del Guadalquivir se encaucen hasta Cádiz, a lo largo de la costa, y sean impulsados también hacia el interior de la Bahía, con mareas favorables. De esta forma se unen aquí las aportaciones fluviales de la mayor parte de Andalucía.

- Los temporales atlánticos alcanzan el frente de la Bahía con toda su intensidad y la fuerza del oleaje se incrementa considerablemente en el estrecho tramo de la plataforma continental que bordea las islas, para chocar con gran fuerza contra el afloramiento de areniscas deleznables, que va siendo desmenuzado en sus capas menos consistentes.

- La regeneración de las playas mediante la aportación de arenas por el viento de Levante disminuye notablemente con la existencia de edificaciones que forman barrera a los aires procedentes del interior, mientras que el vendabal de Poniente actúa con toda su intensidad en el frente litoral desprotegido, con una dinámica bien conocida en Cádiz y que ha sido en la historia reciente de la ciudad un motivo básico de preocupación.

Como síntesis de los principales efectos que esta dinámica produce en el soporte geológico de las islas gaditanas, deben anotarse: la regresión de la costa, o pérdida progresiva del frente de areniscas, erosionado por los temporales, y la colmatación acelerada de la Bahía, en la que los aluviones del Guadalete no encuentran salida y se ven incrementados por los que impulsa el océano desde la desembocadura del Guadalquivir.

De esta forma las islas gaditanas han perdido desde época fenicia una buena parte de su contorno marino, posiblemente el de mayor altura, dada la inclinación del afloramiento de areniscas. Para apreciar las dimensiones que pueden haber tenido estas pérdidas basta observar la posición actual, en la 
playa de Santa María del Mar, de los restos de las fortificaciones levantadas a mediados del siglo XVIII, que han sido demolidas por el oleaje y yacen hoy a unos cincuenta metros al interior de la línea de pleamar (Figura 1). Si la progresión erosiva de la costa ha sido de la misma intensidad en los últimos tres mil años, la plataforma de arenisca que soporta a la ciudad de Cádiz puede haber perdido más de un kilómetro de anchura en este tiempo.

Una transformación aún más notable es la del litoral de la Bahía, colmatado progresivamente, hasta llegar a soldar entre sí las islas primitivas y enlazarlas con la orilla interior. La desembocadura del Guadalete en la Bahía se ha desplazado desde la zona de Rancho Perea y San Isidro del Guadalete hasta El Puerto de Santa María, dejando en seco los embarcaderos romanos y el moderno de Puerto Real. En los mapas del siglo XVI se observa todavía un litoral mucho más profundo entre Puerto Real y El Puerto de Santa María, en el que aún no se había formado la desembocadura del Río de San Pedro. La orilla que mira hacia la Bahía desde las islas gaditanas se ha ensanchado hasta englobar lo que pudieron ser islotes desperdigados, como los de Punta de Vaca, Cerro del Moro y Puntales; el relleno más antiguo e intenso parece el de la zona del Caño de Sancti-Petri, entre San Fernando y Chiclana, que une costas separadas antes más de cinco kilómetros.

La consecuencia de todo ello para el análisis de la topografía primitiva de la necrópolis, es observar que el posible soporte físico primitivo ha sido reducido a una cuarta parte de su extensión en el frente oceánico, mientras que en la Bahía pueden haberse integrado algunos pequeños islotes (véase el mapa general).

\section{CONSIDERACIONES DEMOGRAFICAS}

Aunque los estudios demográficos basados en necrópolis son los más frecuentes y de mayor validez, no se ha llegado a intentar en Cádiz la consideración de todas las tumbas descubiertas en el último siglo como indicio del número y composición de su población primitiva. Don Antonio García y Bellido hizo ciertas observaciones de interés sobre la longevidad de algunas gaditanas (García y Bellido, 1967, p.182) y propuso un cálculo del número de habitantes de la ciudad, a comienzos del Imperio, en 50.000 almas (García y Bellido, 1951, p. 92).

La cifra era propuesta por García y Bellido "en cálculos prudentes", ya que si se tomara como base la referencia de Estrabón a que el censo de los gaditanos contenía 500 caballeros, habría que pensar en una cantidad muy superior; sin embargo, estos 500 caballeros, o "millonarios" en palabras de García y Bellido, podían ser un índice de riqueza más que de superpoblación, lo que llevaría a considerar el posible número de habitantes del Cádiz romano como equiparable, sencillamente, al de los habitantes modernos del casco histórico de la ciudad.

Aunque la ciudad moderna y la antigua no sean coincidentes, la comparación de García y Bellido sigue teniendo validez, puesto que el casco histórico de Cádiz, en el interior de las Puertas de Tierra, tiene un perímetro de longitud similar a los veinte estadios $(3,6 \mathrm{kms}$.) que indicaba Estrabón, y es perfectamente admisible que la abigarrada ciudad fenicia, con sus casas de varios pisos, tuviera una densidad semejante a la de la metrópolis moderna del comercio americano. De esta misma comparación debe deducirse que el mar ha restado a Cádiz tanto espacio como el que sabemos ahora que no corresponde a la superposición de la ciudad moderna sobre la antigua.

Pero si extendemos este cálculo a los restos proporcionados por la necrópolis, debe apreciarse que hoy contamos con mucho mayor volumen de datos epigráficos y sabemos también más sobre la edad de los fallecidos por los estudios antropológicos, de forma que hay aquí un campo abierto para una investigación detallada, que podría ser modélica y muy fructífera. No hay espacio en este artículo para 
acometer algo semejante, ni puede plantearse la investigación de la demografía gaditana sin que se hayan publicado las excavaciones de los últimos doce años, su epigrafía y su análisis antropológico completo.

En cualquier caso, la cifra propuesta por García y Bellido es útil para aproximarnos a un cálculo necesario en la valoración de los datos arqueológicos de la necrópolis, es decir, para intentar calcular cuál es el número probable de enterramientos que pudieron efectuarse en Cádiz durante toda la Antigüedad y compararlo con el número de tumbas conocidas. Las cifras son tan abultadas, que aún aplicando las correcciones y reducciones más prudentes, difícilmente podemos creer que hayamos llegado a conocer más de un diez por mil del total de los posibles enterramientos.

En una aplicación muy restringida del número de habitantes calculado por García y Bellido para la época de Augusto, podemos pensar que la cifra de 50.000 almas puede ser válida sólo para el periodo de los dos siglos de mayor desarrollo de la ciudad, esto es desde César hasta los Antoninos, o sea, desde mediados del siglo I a. C. hasta la mitad del siglo II de la Era. Este número, multiplicado por un índice normal de renovación de la población con cuatro generaciones por siglo, supondría ya 400.000 habitantes.

Para el resto de los siglos de vida de la ciudad deben hacerse estimaciones mucho más reducidas. Desde época de los Antoninos hasta la casi total extinción de la población que se refleja en el poema de Avieno (Or. mar. 270-272), transcurren dos siglos y medio, con unas diez generaciones, cuya demografía decreciente pasaría de 50.000 a 0 habitantes; una pérdida gradual de 5.000 habitantes por generación proporcionaría un total de 275.000 habitantes en este periodo.

Para las épocas anteriores podemos suponer tres fases demográficas distintas: Desde la fundación hasta la plenitud de la época fenicia, en el siglo VI a.C., en que podría alcanzarse una población de 20.000 habitantes, similar a la de las ciudades importantes del momento; un periodo estable desde el siglo V al III a.C., que mantedría el promedio de 20.000 almas y una época de progresivo crecimiento hasta alcanzar en siglo y medio los cincuenta mil habitantes de época de Augusto. El total de la población de estas tres fases sería también considerable: al menos doscientos mil en la primera, doscientos cuarenta mil en la segunda y doscientos cuarenta y cinco mil en la tercera. En total, toda la época antigua de Cádiz daría espacio para un volumen de población cercano al millón cuatrocientos mil.

\section{NÚMERO Y DENSIDAD DE LOS HALLAZGOS FUNERARIOS}

La historia de la arqueología gaditana es rica en testimonios de descubrimientos, al menos desde época musulmana, que se van haciendo más detallados y frecuentes en los últimos siglos; aunque muchos hallazgos pueden no haber sido consignados, tenemos referencias en abundancia que permiten suponer que nuestra información es relativamente completa, y, en el último siglo, prácticamente exhaustiva (Corzo, 1986).

Bien es cierto que los enterramientos no empiezan a despertar un cierto interés arqueológico hasta periodos muy recientes, y que aún en nuestros días se siguen cometiendo expolios y saqueos de tumbas, como los que se registran desde la Antiguiedad, cuyos datos no pueden valorarse; sin embargo, todos los que hemos excavado en Cádiz, sabemos que la mayor parte de las zonas de las necrópolis, aún después de intensas expoliaciones, siguen apareciendo con una riqueza de vestigios muy considerable, tanto de las estructuras constructivas como de los restos óseos, aunque los ajuares hayan desaparecido. 
Para valorar los datos historiográficos es necesario tener en cuenta cuál ha sido el proceso moderno de urbanización de la ciudad. Desde fines de la Antigüedad hasta el siglo XVI, Cádiz fue una población inexistente o muy reducida, que sólo tras la Reconquista cristiana alcanza los estrechos límites de la Villa Vieja, el actual Barrio del Pópulo. Todo el resto de su terreno, dedicado esencialmente a labores agrícolas de poca intensidad, no podría suministrar muchos hallazgos casuales de enterramientos, ya que existe habitualmente sobre ellos una gruesa capa de arena; además, las zonas de explotación agrícola medieval corresponden a lo que hoy es el centro histórico, en el que la necrópolis ocupa zonas muy reducidas.

En la época de crecimiento del Cádiz moderno, desde el siglo XVI al XIX, se urbanizó todo el espacio al norte de las Puertas de Tierra. Los numerosos eruditos gaditanos de esta época registran pocos hallazgos en las obras de nueva construcción, pero siempre lo hacen con especial interés, debido al aprecio secular que aquí se ha tenido por el pasado.

Se conocen en esta época lápidas funerarias y grupos de enterramientos, algunos estudiados y descritos con bastante detalle (Suárez de Salazar, 1610, p. 295). Aunque los ajuares se destruyeran o fueran vendidos, la erudición gaditana no descuidaba la recopilación de epígrafes, de modo que a mediados del siglo XIX se pueden relacionar ya unas ciento setenta lápidas funerarias romanas (Clemente, 1846); esta cifra, si se compara con la proporción de inscripciones que se localizan ahora en zonas bien conservadas de la necrópolis, puede corresponder a unos diez mil enterramientos removidos durante todo este periodo.

En su mayor parte, estas tumbas se localizarían en los estratos superiores de la necrópolis, de baja época romana, que serían los más afectados por las labores agrícolas en la zona extramuros. En el interior de la ciudad, las cimentaciones son de poca profundidad, y sólo se llegaría a alcanzar niveles de enterramientos en los vaciados de los algibes; los sondeos recientes en nuevas construcciones a mayor profundidad, permiten descubrir zonas de enterramientos bien conservados, en los pocos sectores que no corresponden a zonas urbanas o industriales de la Antigüedad o a zonas marinas ahora colmatadas.

A partir del hallazgo en 1887 del sarcófago masculino, los datos de descubrimientos arqueológicos tienen una crónica bien detallada. Pueden calcularse unas tres mil tumbas en las relaciones de excavación de Pelayo Quintero, hasta la Guerra Civil, una fase más imprecisa entre 1940 y 1978, con controles ocasionales de algunas excavaciones y expoliaciones conocidas indirectamente, que podrían suponer un número similar, unos mil enterramientos en los trabajos dirigidos por mí, entre 1979 y 1984, y otros tantos desde esa fecha hasta hoy. La mayor parte de estos hallazgos corresponden a obras de nueva construcción, con vaciado de sótanos y grandes zanjas para canalizaciones o desmontes, como los del trazado del ferrocarril.

Si se marcan sobre el plano del Cádiz extramuros, las zonas excavadas sistemáticamente y aquellas en que las cimentaciones no controladas hacen suponer que la necrópolis ha sido ya destruida, se observa que las expectativas de nuevos descubrimientos quedan reducidas a la mitad de la superficie de la necrópolis, en terrenos nunca edificados o con viviendas de cimentaciones superficiales. Por tanto, es posible llegar aún a otros diez mil enterramientos por excavar, en las previsiones más optimistas.

\section{REPRESENTATIVIDAD DE LOS DATOS ARQUEOLOGICOS}

Este número global de enterramientos ya descubiertos en Cádiz o con posibilidad de ser excavados, no alcanza más allá de los treinta mil, cifra muy considerable para lo que puede desearse en el conocimiento de las tumbas de una ciudad antigua, pero bien escasa si se compara con la apreciación 
demográfica de casi un millón y medio de habitantes en toda la Antigüedad. De otra parte, sólo la mitad de estas tumbas se conoce con cierto detalle o es de esperar que se excaven rigurosamente, por lo que nuestro nivel de conocimientos tendrá siempre una representatividad muy reducida, algo menos de un diez por mil. El cálculo debe matizarse, del mismo modo, en cuanto a la proporción de enterramientos de cada época y en cuanto al nivel económico y social de los fallecidos.

Las razones de la pérdida de tan elevado número de datos deben buscarse, de una parte en la propia evolución de la necrópolis durante la Edad Antigua, y de otra, en la pérdida de una parte muy considerable de su solar.

En las fases más antiguas de la población, cuando los fenicios de Cádiz habitaban "una ciudad muy pequeña", según la referida frase de Estrabón, los enterramientos se concentrarían en lugares que fueron absorbidos por el crecimiento urbano de la nueva ciudad de los Balbos. La necrópolis fenicia ha proporcionado restos muy dispersos, tanto en la pequeña isla de Juno, como bajo la ciudad romana y en terrenos mucho más alejados.

Más adelante, el cementerio romano, ordenado a lo largo de la Vía Augusta, ocupó una franja alargada de terreno de cerca de dos kilómetros de extensión, desde la ciudad hacia el sureste, pero dejando zonas libres para el cultivo, de modo que las tumbas fenicias fueron saqueadas en algunas zonas por los nuevos enterramientos que se les superpusieron, y en otras se mantuvieron bajo el campo. La mayor parte de los enterramientos conocidos anteriores a época romana, no tienen otras tumbas sobre ellos o se encuentran a gran profundidad; cuando la necrópolis romana se superpone a la fenicia, ésta aparece saqueada para reutilizar sus materiales o expoliar sus ajuares, y el reaprovechamiento de los enterramientos o el periodo de respeto y atención a una tumba romana, no parece ser nunca superior a un siglo.

De todo ello, se deduce la necesidad de introducir una reducción drástica en el cálculo de las posibilidades de conservación de una tumba, respecto al número total de habitantes. En las condiciones observadas habitualmente, a cada tumba conservada corresponde, al menos, otra anterior expoliada, y ésto significaría que sólo tendrían posibilidad de haber llegado hasta nosotros unos setecientos mil enterramientos.

En otro orden de cosas, tampoco puede pensarse que todos los antiguos habitantes de la ciudad llegaran a tener aquí una tumba con posibilidades de pervivencia; dice también Estrabón que muchos de los gaditanos vivían en el mar, lo que viene a significar que también muchos morirían en el curso de las navegaciones o en puertos alejados de su patria; en cualquier caso, una población portuaria, con su abundante proporción de gentes de escasos recursos y vida azarosa, daría muchos más cadáveres al mar y al aire que a la tierra protectora.

La reducción que imponen estas consideraciones es muy difícil de valorar, pero debe ser tan abultada como para acercar los cálculos demográficos a la evidencia de los hallazgos.

No hay razones para pensar que la parte conservada de las necrópolis de Cádiz tuviera una densidad distinta de la parte que el mar ha destruido. Si en las primeras consideraciones sobre la conservación del soporte físico se podía evaluar esta destrucción en las tres cuartas partes del solar originario, la multiplicación por el número de tumbas posibles en la cuarta parte conservada, lleva a pensar que en el conjunto de todos los antiguos cementerios de Cádiz se podían haber conservado unos ciento veinte mil enterramientos, de los doscientos cuarenta mil que llegarían a efectuarse en la realidad, correspondientes a una sexta parte de la población total, que sería la que podría haber tenido un sitio temporal en la ciudad de los muertos.

Todos estos cálculos pueden ser muy aproximados y sujetos a revisiones más precisas, pero me parece que dan un panorama aceptable de los elementos que pueden tenerse en cuenta para conocer la 
demografía antigua de la ciudad y la relación entre ésta y las necrópolis; el tema está abierto a una investigación pormenorizada, que podría convertirse en una aportación fundamental al conocimiento de la antigüedad gaditana.

\section{TIPOS Y EPOCAS DE LOS ENTERRAMIENTOS}

El número total de enterramientos conocidos en la necrópolis de Cádiz, proporciona también ciertas indicaciones, si se ordenan los vestigios en su secuencia cronológica.

Sólo conozco una tumba de inhumación que pueda considerarse anterior a las incineraciones fenicias. Se trata de un enterramiento con el cadáver colocado sobre el costado izquierdo, con los brazos y las piernas flexionados, y cubierto por grandes trozos de cerámica, que corresponden a ánforas fenicias a torno anteriores al siglo VI a.C.; se encontró en 1984 en un solar de la Plaza de Asdrúbal, depositado directamente sobre el terreno natural y sin otras indicaciones de fosa que algunas piedras irregularmente dispuestas alrededor del cadáver; tampoco tenía ajuar alguno (Figura 2).

Aunque en el mundo fenicio existan enterramientos antiguos de inhumación, el carácter aislado del enterramiento, a casi tres kilómetros de la ciudad, la falta de indicios sobre un ritual o ajuar fenicio y la semejanza con el tipo de tumbas de los pueblos indígenas de la región a fines de la Edad del Bronce, llevan a relacionar esta tumba con algunos hallazgos dispersos en la misma zona de niveles arqueológicos con restos de carbones, instrumentos líticos poco diferenciables y cerámicas hechas a mano y a torno mezcladas, que parecen indicar un poblamiento ocasional de pequeñas chozas de pescadores o mariscadores indígenas, que conservarían buena parte de los rasgos culturales propios.

Otra tumba muy antigua pudo ser la que contenía la figura de bronce llamada "sacerdote de Cádiz", conservada en el Museo Arqueológico Nacional (Quintero, 1929, p. 9). Aunque en los informes de su hallazgo no se consigna nada concreto sobre el contexto arqueológico, el ilustre aparejador y académico, don Manuel Accame de Campos, que estuvo presente en aquellas obras, me ha asegurado su parecer de que se trataba de un enterramiento, posiblemente de incineración, ya que estaba asociado a algunas vasijas completas y a bastante profundidad.

En este caso sería un tipo de incineración en urna, en el fondo de un pozo, similar a los de la necrópolis fenicia de Almuñécar (Pellicer, 1963), del siglo VIII o VII a.C., y estaría situado en la zona extramuros de la pequeña Isla de Juno, a poca distancia de la colonia fenicia.

\section{CREMACIONES FENICIAS}

A fines del siglo VII a.C. y al siglo VI a.C., corresponde una serie de dieciocho enterramientos, excavados a partir de 1985 (Muñoz Perdigones, 1990). Son tumbas aisladas o agrupadas en pequeño número, a veces superpuestas, en las que el cadáver era incinerado sobre una pira en una fosa, cuyo rebaje inferior servía también para contener los restos de la cremación. Los ajuares son escasos o inexistentes; a veces algún platillo, una lámpara o un ungüentario, y como muestra de mayor riqueza pequeñas joyas deterioradas en la cremación, de poco valor material, aún dentro de su gran interés artístico.

Las cremaciones son imperfectas, puede que por pobreza de los difuntos o, sencillamente, por la escasez y carestía que podrían tener unas maderas adecuadas en una isla pequeña, de escasa riqueza forestal. La carencia de urnas, de ajuares añadidos tras la incineración o de indicios sobre un ritual algo más complejo, como podría ser la separación y lavado de los restos óseos, indican, con mayor seguri- 
dad, que no corresponden a personajes de un gran nivel económico o social, ni con grandes preocupaciones religiosas; tampoco evidencian mayor respeto a las tumbas anteriores, puesto que algunas se cortan entre sí, ni se acogen a una orientación solar estricta.

Desde luego, podría esperarse en Cádiz la aparición de enterramientos comparables a los de Trayamar (Niemeyer-Schubart, 1976), y nada obliga a pensar que estas tumbas sean las más representativas de todo lo que fue el periodo más antiguo de la colonia, con varios siglos de duración y un número potencial de enterramientos superior a los doscientos mil. Para todo este momento tenemos que contar con un porcentaje del uno por diez mil de tumbas conocidas, quizás entre las de menor nivel económico.

Las tumbas fenicias de incineración del siglo VI a.C., o anteriores, se localizan hasta el momento a más de dos kilómetros de distancia de la ciudad, lo que puede ser también un índice de marginalidad. Debemos pensar, por tanto, en una carencia casi completa de información sobre la necrópolis fenicia más antigua, salvo los pequeños indicios de ritual que se deducen de estas dieciocho tumbas y el valor indudable de sus pequeños ajuares para conocer los primeros pasos de la técnica y la iconografía de la orfebrería fenicia gaditana. Más cerca de la colonia, quizás en las zonas que han sido destruidas por la erosión marina, debió existir una necrópolis fenicia más rica y más densa, de la que aún puede aparecer algún vestigio en zonas del actual casco histórico.

\section{INHUMACIONES FENICIAS}

El conjunto de tumbas prerromanas de inhumación de Cádiz se atribuye a unas fechas que, genéricamente, suele establecerse entre los siglos V y III anteriores a nuestra Era. Es evidente, por los testimonios recogidos hasta el momento, que desde el siglo $\mathrm{V}$ a.C. hasta comienzos del Imperio romano, el ritual de incineración no se emplea en Cádiz; como se verá más adelante, tampoco hay indicios de que la presencia romana influyera sobre el ritual funerario durante los siglos de la época republicana, de forma que nada indica con exactitud la diferencia entre las tumbas atribuidas al siglo III, al II o al I antes de Cristo, salvo alguna pieza ocasional de cerámica, que en ningún momento es muy demostrativa.

Es también habitual denominar a estos enterramientos "púnicos". Cuando hace veinte o treinta años, autores como García y Bellido manejaban este término, no parece que le otorgaran un significado equivalente a "cartagineses", sino a "fenicios de Occidente", tal y como se empleaba en los escritores clásicos. La tendencia reciente a supervalorar el papel de Cartago sobre otras colonias fenicias occidentales (Moscati, 1989; Frutos, 1991), hace necesario matizar el uso de este calificativo. La arqueología gaditana es suficientemente personal y bien distinta de la de lugares españoles dependientes de Cartago, como Ibiza o Villaricos, por lo que no se la debe confundir en un mismo grupo cultural; conviene aplicar el nombre de "gaditano" o "fenicio de Cádiz", como se mantenía en época romana, para todo lo que proporcione la ciudad que sea anterior o ajeno a la presencia romana; desde luego, debe evitarse llamar "púnicas" a piezas tan fenicias como los sarcófagos antropoides, que ni siquiera se conocen en Cartago, al menos hasta que se clarifique esta terminología, para no provocar mayores confusiones y respetar el papel y la personalidad de Cádiz en la Antigüedad.

Las tumbas gaditanas de inhumación están representadas por suficientes ejemplares como para formar una tipología amplia. En cualquier caso, son de estructura sencilla, siempre de enterramientos individuales, aislados o en grupos, y se construyeron con los materiales naturales de la isla, por lo que su aparente paralelismo formal con tumbas de algunas poblaciones antiguas del Mediterráneo occiden- 
tal debe hacerse siempre con ciertas reservas; parece aceptable que tengan una vinculación más directa con las necrópolis de localidades costeras del Marruecos atlántico (Muñoz, 1983/84), precisamente por el influjo de Cádiz sobre esta región, recogido repetidamente por los autores clásicos.

Los ajuares de estas tumbas son escasos y poco homogéneos; a veces no existen, en otros casos son sólo piezas de orfebrería correspondientes a la indumentaria del difunto; hay algunas que se acompañan de pequeñas piezas cerámicas: platillos y ungüentarios, y sólo en contadas ocasiones hay vasos y joyas en la misma tumba. Por todo ésto, la fecha de las tumbas es imprecisa, ya que tampoco se cuenta con superposiciones claras.

El modelo más singular de los enterramientos gaditanos es el de los sarcófagos antropoides (Rodríguez de Berlanga, 1891; Blanco-Corzo, 1981). En cuanto a la calidad de los ferétros de mármol (Figura 3 ), debe señalarse que son las mejores piezas de la arqueología española prerromana y únicas en el Mediterráneo occidental, pero de todas sus características singulares haré aquí referencia sólo a las que permiten encuadrarlos junto a otros enterramientos de la ciudad, por su disposición constructiva o su contenido.

Los sarcófagos estaban rodeados por sillares de arenisca, que en el caso del femenino formaban un ajustado forro a la caja de mármol, labrada cada pieza expresamente y ahuecados los sillares de la cubierta para evitar el roce con la tapa (Corzo, 1979/80); el masculino tenía también una protección de sillares, pero no puede apreciarse en las fotos y descripciones del hallazgo si se ajustaban a su forma, aunque en este caso había otras dos tumbas de sillería adosadas a los pies.

Las cámaras funerarias individuales, similares a las que contenían los sarcófagos, son el tipo de enterramiento gaditano de mayor monumentalidad (Muñoz,1984). Se han encontrado estas cámaras, adosadas o con paredes comunes, en grupos de hasta más de veinte enterramientos, que pueden estar comunicados por pequeñas perforaciones. En los ajuares nunca se hallan vasos con ofrendas, ni indicios de que el cadáver haya estado acompañado por objetos preciosos; se limitan éstos a ciertos amuletos, normalmente ensartados en collares, y las joyas de uso más personal, cómo anillos signatarios y pendientes cerrados.

En este aspecto, coinciden con la austeridad observada en el interior de los sarcófagos antropoides; el masculino solo contenía los restos óseos y en el femenino no había más que un escarabeo y cuatro pequeños amuletos. La inscripción del sarcófago antropoide de Tabnit de Sidón (CIS, II, 1, 12), previene ya sobre la falta de objetos valiosos en su interior que pudieran excitar la codicia de los saqueadores; los fenicios de Cádiz, o al menos una parte de los estamentos superiores de la ciudad, conservaron durante siglos esta preocupación que podía garantizar la mejor conservación de sus restos.

Algunos grupos de tumbas de inhumación componen conjuntos extensos y de profundidad considerable. Los excavados por Pelayo Quintero se aprecian en las fotografías como nichos profundos, abiertos por la cabecera (Figura 4), ya que se localizaban en escarpes de los bordes de la isla, erosionados de antiguo, pero otros conjuntos de hallazgo más reciente se han estudiado en su disposición completa (Perdigones-Muñoz, 1990). Similar a estos últimos y de mayor extensión es el grupo que excavé en 1984 en la Plaza de Asdrúbal, formado por nueve cámaras con medianeras comunes, cuyo proceso de construcción puede describirse detalladamente.

Para disponer estas tumbas se hizo una excavación muy profunda, hasta unos tres metros de profundidad, que llegaba a cortar el firme de roca ostionera (Figura 5); en la primera fase se dispusieron cinco cámaras, formadas por tres hiladas de sillares en cada pared, que sirven de apoyo común a las cubiertas; después se añadieron otras dos cámaras paralelas hacia el sur, con la misma orientación y, finalmente, otras dos perpendiculares a las últimas, que no pudieron ser excavadas totalmente, por encontrarse bajo la calle actual. Todas estas cámaras estaban comunicadas por pequeñas aberturas, que 
en algún caso parecían haber sido ensanchadas para reutilizarlas, o por algún saqueador; sin embargo, ni siquiera las del extremo norte, perfectamente cerradas y comunicadas sólo por estrechas ranuras que no permiten el paso de un brazo, proporcionaron restos bien conservados, ajuares o restos de ofrendas. La cámara central de las cinco primeras conservaba un hueco en la cubierta de la cabecera, tapado con una piedra menor (Figura 6), y parecía ser la destinada a mantener la relación con el mundo exterior de todo el conjunto; era, asimismo, la única que conservaba unas mínimas muestras de cierta dignidad o prelación, puesto que junto al cadáver se habían depositado un lote de catorce tabas de hueso, y la difunta conservaba dos escarabeos, sin montura, y dos pequeños pendientes de oro macizo.

No puede pensarse que estas pequeñas piezas sean un ajuar de categoría semejante a la de la arquitectura de las cámaras, ni podría atribuirse su pobreza a saqueos importantes, puesto que no se encontró ningún fragmento de cerámica, ni el más leve indicio de ofrendas; por el contrario, el cierre hermético de las cámaras y la conservación exclusiva de un pequeña capa de tierra ennegrecida, formada por la descomposición de los cadáveres en el agua que se había filtrado por pequeñas fisuras, indican que en estos enterramientos no existieron ataúdes de madera con aplicaciones metálicas o mobiliario de lujo, sino, tan sólo, los cuerpos envueltos en sudarios y recogidos quizás en sencillas cajas. A la difunta que ocupaba la cámara central se le permitió, excepcionalmente, que conservara sus pequeños pendientes de oro, quizás porque su diseño sólo permite retirarlos tras deshacer las espirales de los alambres y debían ser joyas de uso permanente; asimismo se la enterró con dos escarabeos desmontados que ya nadie debería utilizar, de forma semejante a lo observado en la destinataria del sarcófago femenino, y se le agregaron unas tabas de claro sentido mágico y adivinatorio.

En excavaciones posteriores del mismo solar (Perdigones-Muñoz, 1990, p. 35 ss.), aparecieron dos grupos menores de tumbas similares; se encontraban también a bastante profundidad, sin ajuares y con perforaciones de comunicación; las cámaras son de menor altura, realizadas sucesivamente. Junto a ellos se han publicado otros conjuntos de parecidas características, sin ajuares o con pequeñas joyas muy personales, pero siempre sin indicios de ofrendas alimentarias o piezas cerámicas.

Este ritual, con su ausencia de ajuares y la colocación de los enterramientos perfectamente sellados, pero sin accesos exteriores ni signos monumentales, parece indicar la misma preocupación especial por la conservación inalterada de los cadáveres, que manifiestan los sarcófagos. Por tanto, las tumbas gaditanas en cámaras de sillería formando panteones familiares muy reservados, indican la aceptación de unas ideas religiosas, que dan prioridad al mantenimiento pacífico de los restos, en espera de una cierta resurrección o vida de ultratumba, y este pensamiento debe tener un origen bastante directo en la cultura egipcia. Desde luego, aunque pudieran señalarse semejanzas técnicas y formales con tumbas de tipo púnico, no se ha reconocido en la cultura cartaginesa ninguna manifestación de una ideología similar, y debe verse en estos enterramientos una aportación oriental, que llegó directamente a Cádiz y tuvo especial arraigo en una parte importante de su población más acomodada.

Hay otras tumbas de inhumación de la misma época, que parecen indicar un ritual distinto. En el mismo solar de la Plaza de Asdrúbal en el que se encontró el panteón mencionado, aparecieron unos cincuenta enterramientos más de inhumación, protegidos o no con sillares y piedras, que estaban a una altura superior, muy cerca de lo que debía ser la superficie antigua del terreno, y dispuestos con cierto orden y orientación uniformes (Figura 7). No se apreciaron signos exteriores, como estelas, pero su aspecto es el de un cementerio público, en el que se podía identificar con claridad el sitio de cada tumba.

En los ajuares de estos enterramientos hay joyas con cierta regularidad, por lo común, un anillo y un par de pendientes, de oro batido sobre un núcleo de bronce o laminado en cintas como piezas de pura apariencia, que no podrían haber sido empleadas en vida (Figura 8); también se encuentran unguienta- 
rios y pequeños cuencos (Figura 9). Ejemplos de estos enterramientos se encuentran en casi todas las excavaciones publicadas, aunque éste puede ser el sitio de mayor concentración y regularidad, quizás por que no fue alterado por otras tumbas posteriores.

Las tumbas gaditanas de inhumación aparentan una evolución temporal hacia tipos cada vez más pequeños y sencillos; en las que podríamos identificar como más modernas, por la cerámica o la inclusión de alguna moneda de las series locales antiguas, puede llegar a faltar la protección de piedras, de modo que la tumba era una simple fosa cubierta de arena, en la que siempre el cadáver conserva una disposición compacta por haber estado envuelto en un vendaje o sudario apretado (Figura 10) .

Algunos grupos de enterramientos con cámaras de sillería, como el excavado en la calle Bellavista en 1983 (Figura 11), mantiene la forma arquitectónica de los primeros panteones familiares, con materiales constructivos más modestos y ajuares más complejos, en lo que pueden indicar los escasos vestigios conservados tras sucesivas expoliaciones.

Este tipo de inhumaciones gaditanas revela un pensamiento sobre la muerte como hecho social, en el que parece importante la presentación del cadáver con unos ciertos signos de riqueza; de ahí el uso de esas joyas de apariencia, tan abundantes en hallazgos antiguos, como los anillos de piedra giratoria, que no tienen más que una finísima lámina de oro sobre el núcleo de bronce y cuyo engaste es un modesto granate pulido, sin los rasgos del escarabeo ni el entalle identificativo; las joyas imitadas en delgadas láminas de oro que se encontraron en la Plaza de Asdrúbal debían tener como objetivo la dignificación del cadáver en los funerales públicos con los medios menos costosos.

De otra parte, el cadáver acompañado por pequeños vasos indica la creencia en un cierto viaje a otro mundo, en el que es necesario reponer fuerzas, llevar una lamparilla para iluminarse o algún ungüento purificador; debían pensar que el difunto abandonaba definitivamente sus restos, con algo de su parte material, a la que serían de utilidad estas ofrendas hasta alcanzar un nuevo estado. La concepción es muy distinta de la observada en las otras inhumaciones, en las que parece que el alma del difunto no precisa ningún sustento, pero sí va a necesitar la perduración completa de sus restos materiales.

El segundo tipo de inhumaciones fenicias, parece corresponder al común de la población de la ciudad durante varios siglos. Algunas deben ser contemporáneas de las incineraciones de tipo romano, pero los ajuares son tan escasos y monótonos, que no han permitido, por el momento, diferenciar una evolución cronológica en el rito o la forma de la tumba. En Cádiz, es notorio que se empleó muy poco la vajilla romana de barniz negro ("campaniense") o la posterior de barniz rojo ("sigillata"); desde luego, las pocas muestras recogidas no pertenecen nunca a los enterramientos, en los que parece mantenerse siempre un tradicionalismo fenicio, tanto en las ofrendas como en la indumentaria. Resulta tambien significativa la ausencia de fíbulas en todas las épocas, como si se hubiera mantenido siempre en la ciudad el uso de la túnica cerrada oriental, sin mantos ni clámides abrochados con prendedores.

A falta de otros indicios cronológicos, podemos atribuir estas tumbas a un amplio periodo, entre los siglos V y I antes de Cristo, en el que hemos supuesto una población total de más de quinientos mil habitantes, de los que sólo cabe esperar que haya conservado su lugar de enterramiento, unos quince mil. Las tumbas encontradas y documentadas no sobrepasan el número de quinientas, con una representatividad de sólo el uno por mil sobre el total de la población estimada, pero del treinta por ciento sobre las expectativas de hallazgos. Dado que los conocidos se concentran en grupos de poca extensión, hay que considerar que pudieron existir muchos otros grupos, desaparecidos por la erosión marina o por expoliaciones, que podrían representar tipos y rituales distintos.

En cuanto a la posición económica de los difuntos, estos enterramientos de inhumación revelan dos actitudes distintas: la de las familias y grupos que adquieren un lugar y preparan todo un conjunto de cámaras de sillería con cierta antelación, para ir depositando allí los cadáveres de sus miembros, y las 
de los que sólo en el momento del fallecimiento son destinados al lugar disponible dentro de un terreno en el que ya hay otros enterramientos dispuestos en el mismo orden.

Podría pensarse en cementerios públicos y privados, que a veces se superponen, pero que no coinciden nunca en el mismo lugar y tiempo. Sólo en los grupos "familiares" se aprecia una cierta consideración privilegiada a alguna cámara, quizás la del fundador del panteón, mientras que en las zonas públicas nunca se observa subordinación o rasgos constructivos que hagan suponer una primacía de alguna tumba sobre las circundantes.

La estructura social que indica esta organización es sólo de jerarquías económicas, no de predominio político, religioso o militar; en ningún caso los ajuares contienen objetos que destaquen el papel social del difunto y es completa la ausencia de armas, tan frecuentes en las necrópolis ibéricas contemporáneas, lo que confirma la escasa presencia del estamento militar en una ciudad eminentemente mercantil.

\section{INCINERACIONES ROMANAS}

La vuelta al ritual de incineración coincide en Cádiz con el inicio del periodo imperial romano. Si la evolución demográfica indica ya que éste es el momento de mayor densidad, también los datos arqueológicos señalan una presencia prioritaria de las incineraciones, con formas muy variadas. Hay una coincidencia bastante aproximada entre el ritual de incineración y la fase imperial antigua, para la que se puede estimar una población total de cuatrocientas mil almas; el cálculo de las expectativas de hallazgos no sobrepasa, sin embargo, el número de diez mil enterramientos, de los que se conocen ya con exactitud aceptable unos cinco mil. En la misma línea de correlación de datos porcentuales, puede decirse que la población gaditana de este periodo se conoce ya en un uno por ciento de sus enterramientos, y que ésto supone la mitad de los que pueden ser excavados.

Contamos aquí con una cifra bastante más representativa que en los periodos anteriores, por causas claras: al tratarse de enterramientos más superficiales han sido descubiertos con mayor frecuencia y en casi toda la extensión de los solares afectados; su tamaño reducido y la escasez de elementos monumentales o constructivos hace que sea menos frecuente su hallazgo ocasional y expolio; tampoco se observan deterioros notables en la antigüedad por la superposición de tumbas más modernas, que suelen ser menos frecuentes y más pobres.

Dentro del grupo de incineraciones romanas han de incluirse los columbarios o cámaras con nichos para urnas cinerarias. Se conocen varias de estas construcciones, siempre muy saqueadas por su mayor prestancia arquitectónica, pero suficientes para indicar la existencia de panteones familiares de uso dilatado.

Los enterramientos de incineración corresponden a tipos muy variados, desde la simple fosa en la arena, llena de carbones y cenizas, hasta urnas de mármol de gran valor. Las cremaciones se podían hacer en cualquier lugar, aunque es fecuente el hallazgo de fosas revestidas de opus signinum, como una pileta hidráulica, calcinadas por las sucesivas ceremonias y con restos de carbón en su interior. Estas fosas permitirían la recogida de los restos óseos con mayor limpieza, aunque no se ha determinado en ningún caso que estén vinculadas exclusivamente a un grupo de urnas o a un columbario.

En un sector de la necrópolis, excavado en 1982, en la esquina de la calle Santa Cruz de Tenerife con la Avenida de López Pinto, aparecieron muchas incineraciones en las que los restos habían sido cubiertos sencillamente con arena, sin separar los huesos de los carbones, ni modificar su colocación (Figura 12); estas fosas de incineración estaban superpuestas en muchos casos, para ceremonias casi 
consecutivas, de forma, que no pueden considerarse tumbas estables, cuyo lugar se respetase o fuera objeto de conservación, sino simples cremaciones tras las que los cadáveres eran abandonados definitivamente. También existen fosas circulares de pequeño diámetro que contienen huesos y carbones mezclados; están excavadas en la arena, a poca profundidad y sin señales externas; ambos tipos deben atribuirse a los niveles más pobres de la población del momento, sin grandes preocupaciones por la veneración a los muertos, ni confianza en algún tipo de vida ultraterrena que mantuviera contacto con el presente. La única ceremonia aplicada al cadáver es la de la cremación por razones higiénicas.

Junto a las fosas crematorias sencillas, se sortean urnas de distintos tipos, en las que se observan algunas ceremonias más cuidadosas. La variedad de recipientes empleados deben corresponder a ciertas modas o preferencias entre los distintos grupos de población, y, también, a su nivel económico.

Las urnas más baratas y de tipo más tradicional, que podrían hacerse equivaler a las de otras poblaciones cercanas sin una especial tradición fenicia, son de cerámica común, cubiertas con un cuenco y alojadas en fosas protegidas por piedras menudas (Figura 13); las de niveles económicos superiores pueden ser de plomo o de vidrio protegido por una funda de plomo. En una proporción similar de riqueza están los ajuares que las acompañan y los cuidados rituales; las más modestas incluyen restos óseos y carbones, con pequeñas piezas cerámicas o de vidrio alteradas por la cremación; las más ricas ofrecen los huesos lavados y separados de los carbones junto con algunas ofrendas añadidas en el momento del depósito en la urna, perfectamente conservadas.

Otros recipientes comunes de incineración son cajas de piedra ostionera, de pequeño tamaño y labradas con la tapa a dos vertientes; corresponden a la imitación local de las cistas griegas y romanas, empleadas también por las culturas ibéricas. Aunque no puede establecerse una diferencia cronológica entre las cajas de piedra y las vasos de cerámica, plomo o vidrio, parece que las cajas son más antiguas y se destinaban con mayor frecuencia a columbarios, ofreciendo, por lo común, restos óseos bien lavados. También se lavaban con cuidado los restos destinados a urnas o cajas de mármol de mayor calidad.

En todo este periodo, la necrópolis debía reconocerse como un espacio perfectamente delimitado y ordenado, con las tumbas señaladas mediante pequeñas edículas y estelas. La aparición de restos de inscripciones monumentales reutilizadas, como la de la niña Secundilla, que se ha reconstruido en el Museo de Cádiz, confirman que los columbarios tenían un cierto empaque constructivo, aunque sus estructuras externas se expoliaron muy pronto. Esta inscripción de Secundilla, cuyos sillares se emplearon como caja de una inhumación tardía (Figura 14), apareció en 1981 frente a la Iglesia de San José, muy cerca de dónde se había localizado años atrás la urna cineraria y la lápida de su nodriza, que fueron donadas al Museo; parece que el expolio de la zona monumental del columbario, respetó en buena parte las urnas colocadas en su interior.

Pero el monumento funerario más habitual en Cádiz, es la estela formada por un sillar de piedra ostionera, de algo más de un metro de altura, con la parte superior redondeada y un rebaje en el frente destinado a contener una lápida de mármol. Es frecuente hallar estas estelas reutilizadas y las lápidas rotas y desprendidas, puesto que permanecían al alcance de cualquiera. Algunas estelas reutilizadas tienen el frente ordenado con una simulación arquitectónica y ranuras en su parte superior, como si imitaran las canales de un tejado; esta asimilación formal de la tumba a la casa del difunto es tan habitual en el Mediterráneo antiguo, que no cabe atribuirle una vinculación cultural definida. Aunque el uso de estelas sea muy habitual en el ambiente púnico, falta aquí su iconografía peculiar, con la que sólo se ha relacionado, por el momento, una posible representación del símbolo de Tanit.

Los ajuares de las tumbas de incineración contienen piezas normales de cerámica: una lucerna, ungüentarios y algún vaso de paredes finas; son de tipos y fabricación muy uniformes, como productos 
de talleres locales, entre los que se conoce con certeza uno en San Fernando (Corzo, 1981-82), y hay también indicios en la misma zona de la necrópolis, como los hornos de alfarería excavados en 1982 muy cerca de la Puerta de Tierra. En ocasiones, los ungüentarios son de vidrio, de tipos muy homogéneos. Sin embargo, no es posible asociar a ninguna tumba, ni una sola pieza de "terra sigillata"; la vajilla romana de lujo se documenta escasamente en Cádiz, en zonas de habitación, pero está ausente por completo de la necrópolis, como rasgo definitorio de su tradición cultural propia, cerrada a ciertas modas.

También se ha indicado como en los enterramientos fenicios nunca se encuentran fíbulas, lo que se repite en época romana, si hacemos excepción de la famosa fíbula de oro, en forma de moscardón, que es pieza única y de interpretación dudosa; aunque existan algunos ajuares con objetos de tocador y piezas de indumentaria, estos se limitan a botones y agujas de hueso, cajas de afeites, pinzas y espejos de bronce, marcando una autonomía muy destacada en la aceptación de ciertas modas, que no tuvieron obstáculo alguno en toda la región andaluza.

En ningún periodo histórico manifestaron los antiguos gaditanos predilección por ricos ajuares funerarios, y de los pocos que existieran, casi nada se ha salvado de las expoliaciones. Como muestra del nivel más elevado de ofrendas funerarias que podrían acumularse en un enterramiento de incineración de época imperial, puede tomarse en consideración la llamada Tumba Pascual, con un número considerable de vasos de lujo: dos jarras de gollete alargado, dos cubiletes abiertos, un cuenco de paredes finas, una jarra con colador, dos cuencos pintados y tres vasitos de vidrio de calidad excepcional; además contenia un huevo de gallina intacto y dos anillos de oro con magníficos entalles. Está claro que el difunto prefería los objetos de origen oriental en el servicio de mesa, como los cuencos pintados y los vasos de vidrio, que corresponden a una producción alejandrina; no se hizo acompañar por ungüentarios, ni por los habituales lacrimatorios romanos de vidrio, y entre las joyas, sólo consideró necesario conservar los dos anillos signatarios, de considerable precio y con claras huellas de uso prolongado. Esta preferencia por los entalles recuerda el caso ya referido de una tumba fenicia de la Plaza de Asdrúbal, con dos escarabeos, y el que conservaba el sarcófago femenino, como única joya personal; también en muchas tumbas fenicias gaditanas se incluía un anillo de apariencia, con escaraboide giratorio para sellar. De otra parte, el huevo de gallina aparece en las tumbas ibéricas y recuerda el tradicionalismo cartaginés de los huevos de avestruz pintados. Parece significativo que la tumba de incineración más rica, señale, precisamente, a un personaje claramente apegado a tradiciones orientales arraigadas de antiguo en la ciudad.

\section{INHUMACIONES ROMANAS}

Durante el siglo II de la Era se produce el nuevo cambio de ritual, para abandonar definitivamente las incineraciones. Este cambio pudo ser progresivo, ya que en algunas zonas con abundantes incineraciones, como la excavada en 1979 y 1980 en la Avenida de López Pinto, se observa que éstas se alternan con fosas de inhumación; en un caso pudo observarse como la parte central de un columbario se había empleado para alojar tres tumbas paralelas de inhumación, con ajuares que pueden ser de fines del siglo I, o comienzos del II de nuestra Era. Hay también inhumaciones con ajuares de tipos muy corrientes, como el cuenco y el ungüentario de cerámica común, que no se diferencian en sus formas de otros que se encuentran en incineraciones, pero la tipología debe establecerse con mayor precisión, para saber su fecha segura.

En cualquier caso, las inhumaciones más pobres, con materiales constructivos reutilizados y practicamente sin ajuares, vienen a coincidir con los niveles más recientes de la necrópolis, y, consecuente- 
mente, con la última fase de la antigua población gaditana, en su declive económico que llegaría hasta una desaparición casi completa. La proporción de enterramientos encontrados frente al total estimado de la población, ofrece un porcentaje similar al de la fase de incineraciones: el uno por ciento de la población total, que supone casi la mitad de las tumbas con posibilidad de conservación.

Los ajuares de estas tumbas son muy escasos o inexistentes, de forma que no hay criterios claros para fecharlas. Puede pensarse que son más antiguas las que conservan una disposición ordenada y una orientación regular, habitualmente perpendicular al eje de la avenida central del Cádiz moderno, que conserva una traza paralela a la vía romana entre la ciudad y el templo de Hércules. También serían anteriores, y de mayor nivel económico, las tumbas protegidas por tégulas a dos vertientes y las construidas con ladrillos, ya que estos materiales son escasos en Cádiz, dónde es mucho menos costosa la construcción con piedra ostionera. Desde luego, se observa la pérdida de la regularidad de orientación en los enterramientos con material de acarreo y sin ajuares (Figura 15).

Tanto por sus materiales, como por estar en los niveles superiores del terreno, las tumbas de inhumación han sido saqueadas y removidas parcialmente en la mayoría de los casos. El análisis paleográfico de las lápidas de Cádiz invita a pensar que muchas corresponden a los enterramientos de inhumación de los siglos II y III de la Era, cuando la necrópolis mantenía aún su estructura ordenada y ciertos rasgos de monumentalidad. Las estelas con lápidas serían también lo primero que se reutilizaría como material de construcción para otros enterramientos, y no parece que se empleeen ya en el siglo IV.

\section{INHUMACIONES INFANTILES}

Mientras que dentro de los enterramientos fenicios de inhumación, no hay casos documentados de tumbas infantiles, éstas se hacen presentes con claridad en época romana. En Cádiz, como en otros lugares cercanos, se registra la existencia de grupos de enterramientos infantiles, asociados, a veces con claridad, a signos de violencia, que requieren una interpretación específica.

En 1980, excavamos un grupo de tumbas infantiles de inhumación en un solar de la Avenida López Pinto (Figura 16), que permitía pensar en una inmolación ritual de pequeñas víctimas a las que se había golpeado el cráneo con un objeto contundente (Corzo, 1989,2). El tema ha sido expuesto reiteradamente y viene a ponerse en relación con otros ritos peculiares hacia los enterramientos infantiles de inhumación que se registran en distintos lugares de la Península Ibérica y de Baleares durante la Antiguiedad; a ellos se ha dedicado el volumen en que se encuentra mi trabajo mencionado anteriormente, lo que ha provocado una toma de posición enfrentada en otros investigadores (Moscati-Ribichini, 1991), que defienden una interpretación más benévola del sacrificio infantil fenicio que la transmitida por los textos antiguos.

De no ser por ésto, bastaría con mencionar aquí la práctica en Cádiz de un rito especial de inmolación de niños, como hecho connatural a la religiosidad fenicia, pero los comentarios ya publicados obligan a precisar mejor lo que sabemos hoy del asunto.

La numerosa bibliografía reciente sobre la cuestión del sacrificio infantil, (Moscati-Ribichini, 1991, recogen las citas de cincuenta y nueve trabajos publicados entre 1987 y 1991), dedica la mayor atención a valorar la credibilidad que puede darse a las conocidas críticas que se hacían en la Antigüedad a fenicios y cartagineses, como pueblos bárbaros, a los que no repugnaba sacrificar sus hijos primogénitos a dioses sedientos de sangre.

Esta atribución, revivida en la literatura romántica, se quiere ver ahora como la exageración de sus 
enemigos, judíos y romanos, ante una forma de ritual, que mantenían también otros pueblos, y que sólo se realizaría en casos excepcionales; la interpretación real del "tofet" como cementerio infantil, con abundantes pruebas arqueológicas, sería la de un lugar especialmente dedicado a los niños nacidos muertos, o fallecidos en el parto o en los primeros meses de vida por causas naturales, que eran depositados en un lugar independiente, como si su posible vida de ultratumba hubiera de ser distinta a la de los que ya habían entrado a formar parte de la sociedad.

Este argumento de defensa a los denostados fenicios y cartagineses, transforma a judíos y romanos en unos exagerados mentirosos, y tampoco parece razonable pensar que nadie en la Antigüedad supiera apreciar lo que sería un rasgo tan meritorio de especial sensibilidad por la infancia.

El caso es que la interpretación del "tofet" como cementerio infantil privilegiado no resulta nada satisfactoria; es lógico pensar que en la mentalidad fenicia y cartaginesa la ofrenda de recién nacidos o de niños pequeños tenía una función religiosa y social de especial relevancia, más allá de la simple demostración de un afecto hacia la infancia. Precisamente, la constatación en España de la existencia de necrópolis infantiles de inhumación, indica que, con independencia del tipo de rito del enterramiento, la ofrenda de primicias, en forma de recién nacidos, tenía un significado específico en las relaciones de la sociedad con las divinidades, y ésto se traducía en necrópolis independientes o en agrupaciones distintas a las de tipo familiar.

Para concretar estos comentarios al caso gaditano y a los reparos que se hacen a que se encuentren aquí sacrificios infantiles, debo indicar, en primer lugar, a las dudas sobre que los indicios de muerte violenta por contusión se deban a deterioros producidos en el cadáver en épocas posteriores, que esta misma apreciación se había hecho sobre otros enterramientos de la zona de Carmona (Bonsor, 1899), a los que se distingue como "lapidados" por las fracturas evidentes que presentaban, y también sobre tumbas de la localidad costera de Baelo Claudia, muy próxima a Cádiz (París, 1923).

En 1988, se produjo en Cádiz un nuevo hallazgo de enterramientos infantiles, en el que sus halladores apreciaron los mismos síntomas de contusión del cráneo (Diario de Cádiz del 24 y el 26 de mayo de 1988); además, en este caso eran tumbas especialmente protegidas por el pavimento de una construcción, cuyo destino no ha sido aclarado; el hecho de que en época romana se realicen en Cádiz deposiciones de restos infantiles bajo un pavimento no deja de ser un hecho anómalo frente a los usos rituales de la época; ésto invita a buscar una explicación en la costumbre fenicia del "tofet", y en la conocida frase de Cicerón sobre la forma en la que César y Balbo el Mayor se habían preocupado por desterrar de Cádiz ciertas "formas de barbarie" (Corzo/Ferreiro, 1984).

Podría añadirse la noticia de una necrópolis tardía de inhumaciones infantiles en ánforas, excavada en Chipiona en 1989; sé que en estos momentos se efectúa el análisis antropológico, que quizás facilite algún indicio de muerte violenta, aunque ya es bastante significativo que aún en los primeros años del siglo $\mathrm{V}$ de la Era se documente en el área gaditana una zona de enterramientos reservada exclusivamente para niños de escasa edad o recién nacidos; no es éste un uso típico de la romanidad ni de los inicios del cristianismo, mientras que está muy cercano a las formas del "tofet".

Otra dificultad que señalan los investigadores italianos para admitir que el tipo de inhumación infantil gaditana con sacrificio por contusión sea asimilable al rito fenicio del "tofet" (Moscati-Ribichini, 1991, p. 39), es que los antiguos textos ugaríticos que mencionan esta forma de ofrenda de recién nacidos, están muy distantes en el espacio y en el tiempo, y se refieren estrictamente a sacrificios de animales. Ya en el sacrificio bíblico de Isaac por Abraham, se observa la ambivalencia del primogénito humano y el animal, de modo que los sacrificios por "sustitución", bien documentados en los "tofet" cartagineses, revelan que el animal es siempre un recurso para representar a la víctima humana, mucho más apreciable. 
No debe sorprender, en cualquier caso, que en Cádiz pudiera mantenerse un rito fenicio distinto de la incineración habitual en Cartago, ya que hasta fines de la época romana, el ritual fenicio del templo de Hércules gaditano se reputaba como ancestral y se reconocía como distinto de cualquier otro, por su arcaísmo y su remoto tradicionalismo, que causaba sorpresa ante cualquier visitante; la admiración que Filóstrato atribuye a Apolonio de Tiana y muchos otros testimonios de las fuentes clásicas (García y Bellido, 1963), abonan la certeza de que Cádiz se mantuvo siempre apegada a unas formas religiosas implantadas en los primeros tiempos de las colonizaciones fenicias, anteriores a la fundación de Cartago, que eran la señal de prestigio y autonomía de los sacerdotes de Cádiz.

Creo que la tendencia reciente a contemplar el sacrificio infantil de los fenicios como una calumnia exagerada de sus enemigos, deforma innecesariamente una realidad histórica y arqueológica bien comprobada, en la que los fenicios de Cádiz y sus vecinos se manifiestan como seguidores de una creencia y de un ritual muy antiguos. Si muchos de los restos conservados en las urnas de los "tofet" cartagineses corresponden a niños fallecidos naturalmente o a pequeños animales, ello indica, con mayor certeza, que ambos sustituyen, como ofrendas de menor valor, a la víctima preferida que sería la del primogénito humano, tal y como indican las fuentes.

El carácter apartado y oculto que se mantiene para este rito en época romana, evidencia que el "tofet" acogía víctimas no permitidas, lo que no es aplicable a los pequeños animales ni a los niños muertos al nacer, que podrían ser ofrendas públicas y legales; el elevado valor que concedían los fenicios al sacrificio de los primogénitos explica que se recurra también a niños muertos por causas naturales y a víctimas animales, pero siempre en lugares especiales o con ritos distintivos.

Las inhumaciones infantiles son abundantes en Cádiz, quizás más de lo que sería de esperar en una población que hemos visto cómo era frecuentemente descuidada con sus muertos; además, los cadáveres de corta edad son los únicos que se mezclan profusamente con las incineraciones romanas, de forma que en algunos casos podría pensarse que a los niños se les evitaba la incineración para que sus restos mantuvieran un cierto valor de ofrenda completa, que no era ya aplicable a los adultos.

Sin embargo, estas cuidadas inhumaciones infantiles de época romana, no tienen precedentes conocidos en la necrópolis de inhumación fenicia, dónde sólo aparecen los adultos; los niños sólo entran a formar parte del cementerio general en la época en que podemos pensar que las prohibiciones de César y Balbo hacían imposible mantener un sitio especialmente dedicado a ellos. Está claro que desconocemos totalmente una necrópolis infantil fenicia en Cádiz, y ello demuestra que debieron tener destinado un lugar distinto, que no sabemos si algún día pueda ser puesto al descubierto, quizás, en las inmediaciones del templo de Hércules, que en su advocación fenicia de Melkart, sería el destinatario más probable de la inmolación de los primogénitos.

Hay un argumento que considero muy claro para sostener que el fenómeno transmitido por la arqueología de los cementerios infantiles especiales y los indicios reiterados de muerte violenta está en relación directa con el sacrificio ritual, y es que ningún investigador ha podido encontrar en los textos clásicos o en la iconografía un principio religioso que explique este trato especial hacia la infancia; nada sabemos de dioses infantiles, ni de formas especiales de ultratumba que den a los niños un papel distinto al de los adultos; tampoco se han aducido paralelos etnográficos comparables.

El cementerio infantil sólo se conoce en la cultura fenicia y cartaginesa y su fundamento debe estar en la inmolación de los primogénitos; las variantes en las formas del sacrificio o la extensión del concepto de ofrenda a niños muertos por causas naturales y a víctimas animales sustitutorias confirma el valor de este rito, sin que la repugnancia moderna hacia esta idea nos permita buscar otras explicaciones más benevolentes. 


\section{CONCLUSIÓN}

La revisión de los datos cronológicos y topográficos de la necrópolis de Cádiz ofrece un panorama copioso en que he procurado establecer una ordenación global y unos criterios iniciales de valoración.

En primer lugar, se puede observar un inconveniente insalvable en la posibilidad de que la evolución topográfica de las islas haya destruido cualquier vestigio de las necrópolis más antiguas o de sus zonas más ricas. La acumulación de restos en el frente oceánico y la certeza de que allí se encontraba la parte más elevada de las islas y el trazado de la vía principal, llevan a considerar que nuestros conocimientos siempre tendrán que limitarse a zonas marginales o de relativa pobreza.

En segundo lugar, parece claro que la elección del tipo de ritual funerario evolucionó primero de la incineración a la inhumación por la extensión a comienzos del siglo $\mathrm{V}$ a. $\mathrm{C}$. de las ideas egipcias sobre la necesidad de conservación del cadáver como referente del espíritu en su vida ultraterrena; este principio se mantendría en algunos grupos sociales, mientras que otros sólo conservaron el apego a la inhumación como expresión de un acto social. La incineración vuelve a implantarse como extensión de una norma romana, aunque de forma tardía y puede que nunca se aplicara a los enterramientos infantiles, sujetos a la devoción fenicia de ofrenda de los primogénitos. En el siglo II de la Era se vuelve a generalizar la inhumación, cada vez con formas arquitectónicas y rituales más pobres, en lo conocido hasta el momento.

Los ajuares de las necrópolis gaditanas son casi siempre más de apariencia que de verdadero lujo; parece que era suficiente cumplir unas ciertas formas de prestigio social, pero que no se tenía gran confianza en la utilidad para el difunto de un mobiliario costoso o de una reserva copiosa de alimentos. En muchos casos, la urna es de una calidad muy superior a su contenido. Tampoco las incineraciones se efectuaban con grandes medios y el lavado de los restos óseos y las cenizas no suele ser muy cuidadoso; en todo esto puede influir el hecho de que sólo conocemos sectores relativamente pobres de la necrópolis.

Los indicios que facilitan los ajuares sobre la evolución cultural de la ciudad, son de un conservadurismo claro, por la falta de adopción de costumbres romanas, como el vestido con fíbulas o la vajilla de "terra sigillata". Por supuesto, menos penetración aún puede reconocerse de préstamos de los pueblos ibéricos inmediatos, durante la época fenicia. El gran número de habitantes de Cádiz en la Antigüedad debió nutrirse de su propio desarrollo y de la continua emigración de gentes del Mediterráneo oriental, es decir, de poblaciones de orígenes fenicios similares, pero ni los turdetanos, ni los cartagineses ni los romanos, demuestran una presencia, ni tan siquiera ocasional, en las necrópolis.

Es de especial interés el hecho de que no hay paralelos constructivos ni rituales con la cultura cartaginesa, más allá de los inevitables en la cercanía geográfica y de orígenes culturales; no se evidencia ninguna relación con la estructura social y política de Cartago, y desde luego, no hay ningún objeto arqueológico al que se pueda dar la clasificación de "púnico" sin reservas. Además, falta por completo la huella de la escritura cartaginesa, mientras que en Cádiz, como en las comarcas vecinas, parece que el alfabeto difundido fue el fenicio y sus combinaciones con los sistemas de escritura locales.

Finalmente, debe destacarse la escasa perduración o respeto a las tumbas anteriores, en las que son muy frecuentes los indicios de expoliaciones y reaprovechamientos. Como razón primordial está la escasez de espacio que obligaba a superponer los enterramientos, pero también una aparente despreocupación por el mantenimiento de memorias notables de los difuntos; los monumentos funerarios son siempre sencillos y no hay muestras de un culto prolongado, por lo que la ceremonia social de los funerales debía limitarse a los actos inmediatos, sin que importara una amortización rápida del lugar de sepultura. 


\section{BIBLIOGRAFIA}

BLANCO/CORZO, 1981 A. Blanco Freijeiro y R. Corzo Sánchez, "Der neue anthropoide Sarkophag von Cadiz", Madrider Mitteilungen, 22, 1981, p. 236 ss.

BONSOR, 1899. G. E. Bonsor, "Les colonies agricoles prerromaines de la Vallée du Bétis", Revue Archéologique, 35, 1899, p. 15 ss.

CLEMENTE, 1846 J. Clemente, Inscripciones romanas gaditanas, Cádiz, 1846.

CORZO, 1979/80 R. Corzo Sánchez, "El nuevo sarcófago antropoide de la necrópolis gaditana", Boletín del Museo de Cádiz, II, 1979-80, p. 13 ss.

CORZO, 1980 R. Corzo Sánchez, "Paleotopografía de la bahía gaditana”, Gades, 5, 1980, p. 5 ss.

CORZO, 1981/82 R. Corzo Sánchez, "El ceramista Gaius lunius Dracus", Boletín del Museo de Cádiz, III, 198182 , p. 55 ss.

CORZO, 1983 R. Corzo Sánchez, “Cádiz y la arqueología fenicia”, Discurso de ingreso en la Real Academia de Bellas Artes de Cádiz, Anales de la Real Academia de Bellas Artes de Cádiz, 1, 1983, p. 5 ss.

CORZO, 1986 R. Corzo Sánchez, "Historia de la Arqueología gaditana", Cádiz en su Historia, V, 1986, p. 7 ss.

CORZO, 1989-1 R. Corzo Sánchez, "El teatro romano de Cádiz”, Homenaje al profesor Antonio Blanco Freijeiro, Madrid, 1989, p. 187 ss.

CORZO, 1989-2 R. Corzo Sánchez, "Los sacrificios infantiles en Cádiz”, Cuadernos de Prehistoria y Arqueología castellonenses“, 14, 1989, p. 239 ss.

CORZO, 1991 R. Corzo Sánchez, "Cádiz fenicia", I-IV Jornadas de arqueología fenicio-púnica (Ibiza 1986-89), Ibiza, 1991, p. 79 ss.

CORZO, 1992 R. Corzo Sánchez, "El templo de Hércules gaditano en época romana”, Boletín del Museo de Cádiz, V, 1992 (en prensa).

CORZO/FERREIRO,1984 R. Corzo Sánchez y M. Ferreiro López, "Sacrificios humanos en el Cádiz antiguo", II Congreso Andaluz de Estudios Clásicos, vol. II. Málaga, 1984, p. 57 ss.

CORZO/TOSCANO,1992 R. Corzo Sánchez y M. Toscano San Gil, Las vías romanas de Andalucía, Sevilla, 1992.

FRUTOS, 1991 G. Frutos Reyes, Cartago y la política colonial en el Mediterráneo occidental, Ecija, 1991.

GARCIA Y BELLIDO, 1945 A. García y Bellido, España y los españoles hace dos mil años, según la Geografía de Estrabón, Madrid, 1945.

GARCIA Y BELLIDO, 1951 A. García y Bellido, “Iocosae Gades”, Boletín de la Real Academia de la Historia, 1951 , p. 73 ss.

GARCIA Y BELLIDO, 1963 A. García y Bellido, "Hercules gaditanus"

Archivo Español de Arqueología, 1963, p. 63 ss.

GARCIA Y BELLIDO, 1967 A. García y Bellido, Veinticinco estampas de la España antigua, Madrid, 1967.

GAVALA, 1973 J. Gavala y Laborde, El origen de las islas gaditanas, Cádiz, 1973.

MAPA, 1989 Mapa fisiográfico del litoral atlántico de Andalucía, Sevilla, 1989.

MOSCATI, 1989 S. Moscati, Tra Tiro e Cadice, Roma, 1989.

MOSCATI/RIBICHINI, 1991 S. Moscati y S. Ribichini, "Il sacrificio dei bambini: un aggiornamento", Quaderni della Accademia Nazionale dei Lincei, 1991, p. 3 ss.

MUÑOZ, 1983/84 A. Muñoz Vicente, "Aportaciones al estudio de las tumbas de sillería prerromanas de Cádiz”, Boletín del Museo de Cádiz, IV, 1983-84, p. 47 ss.

MUÑOZ/PERDigoneS, 1990 A. Muñoz Vicente, L. Perdigones Moreno, La necrópolis fenicio-púnica de Cádiz, Roma, 1990.

NIEMEYER/SCHUBART, 1976 H.G. Niemeyer y H. Schubart, "Trayamar. Los hipogeos fenicios y el asentamiento en la desembocadura del río Algarrobo", Excavaciones Arqueológicas en España, 90, Madrid, 1976.

PARIS, 1923 P. Paris et al., Fouilles de Belo, II, La necropòle, Paris, 1923

PELLICER, 1963 M. Pellicer Catalán, "Excavaciones en la necrópolis púnica Laurita en el Cerro de san Cristóbal (Almuñécar, Granada)", Excavaciones Arqueológicas en España, 17, Madrid, 1963. 
QUINTERO, 1929 P. Quintero y Atauri, "Excavaciones en Cádiz. Memoria de las excavaciones practicadas en 1928", Informes y Memorias de la Junta Superior de Excavaciones y Antigüedades, 99, Madrid, 1929.

RODRIGUEZ DE BERLANGA, 1891 M. Rodríguez de Berlanga, El nuevo bronce de Italica, Madrid, 1891.

SUAREZ DE SALAZAR, 1610, J. B. Suárez de Salazar, Grandezas y antigüedades de la Isla y ciudad de Cádiz, Cádiz, 1610. Ed. facsímil con notas de R. Corzo, Cádiz, 1985). 


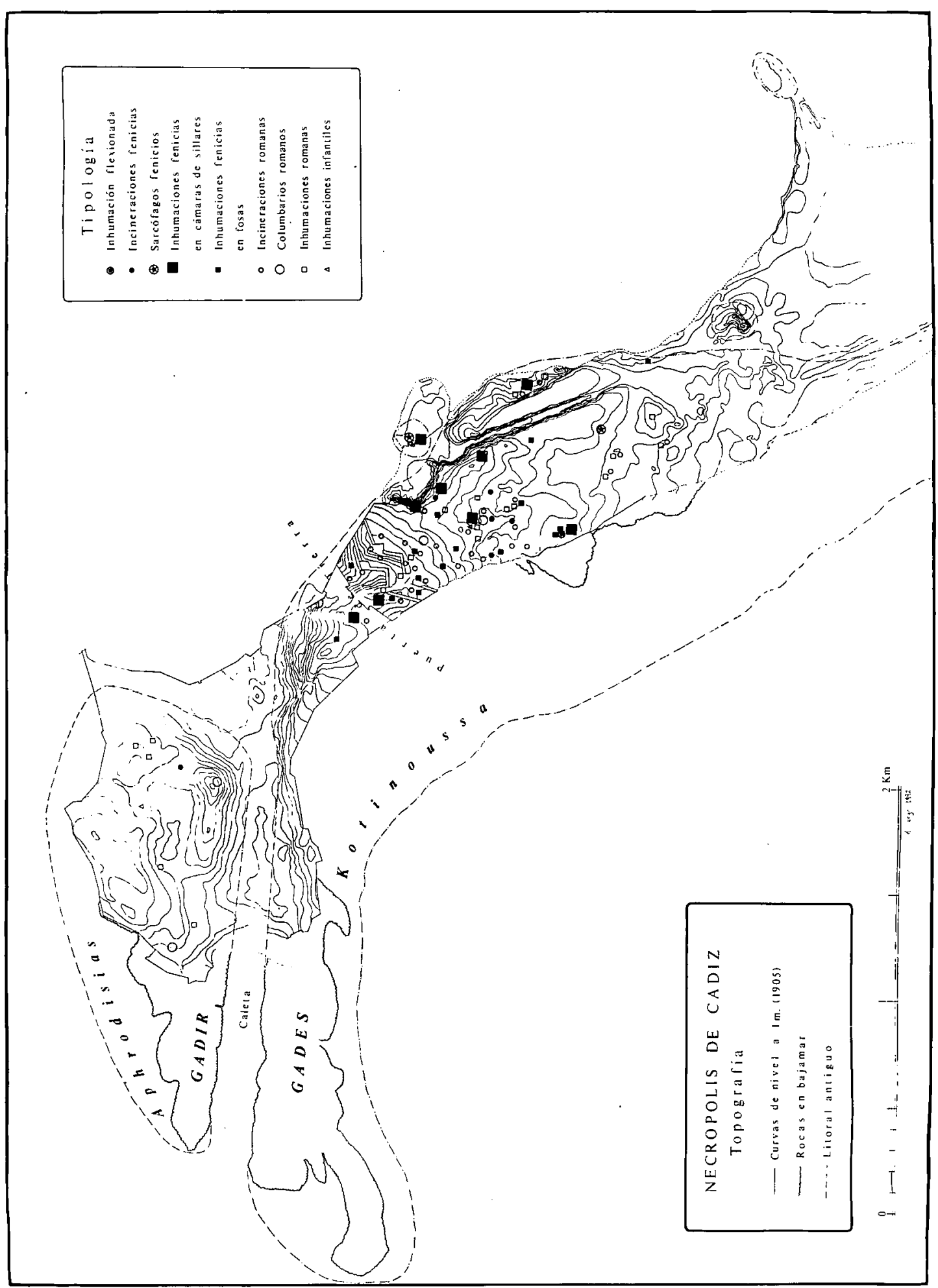

Mapa General de Cádiz 


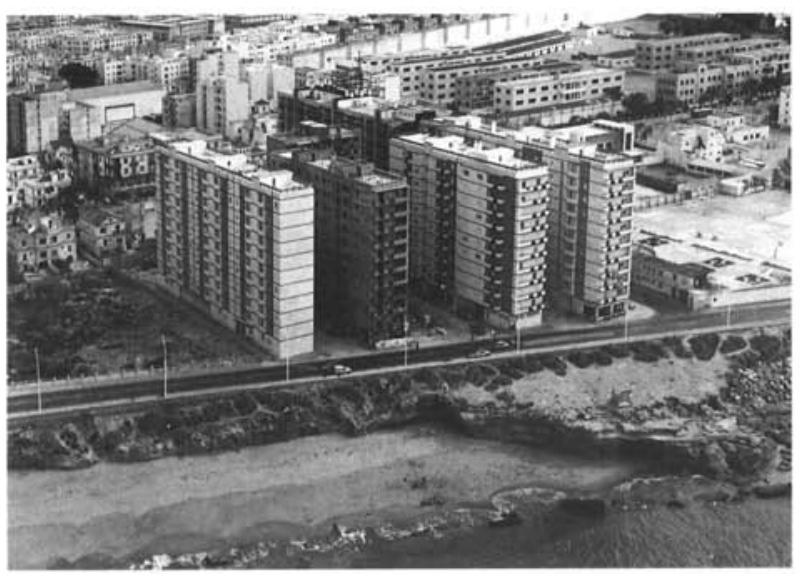

Fig. I

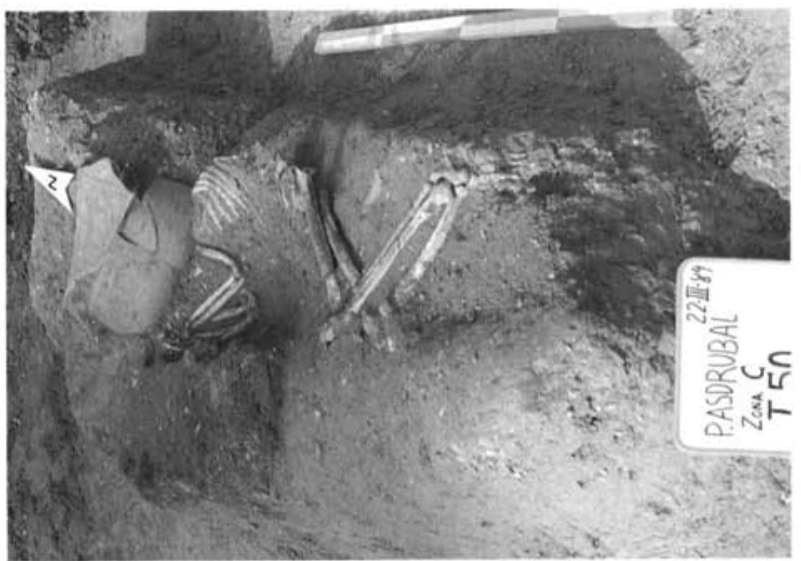

Fig. 2 


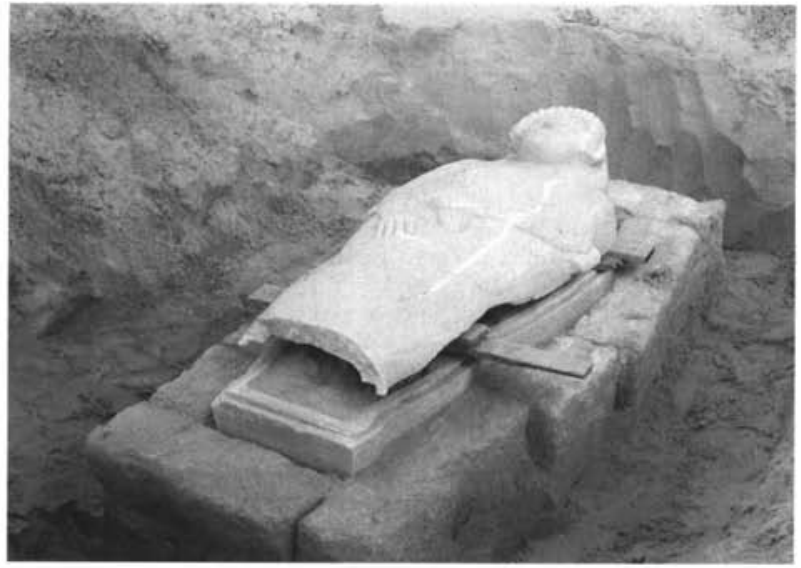

Fig. 3

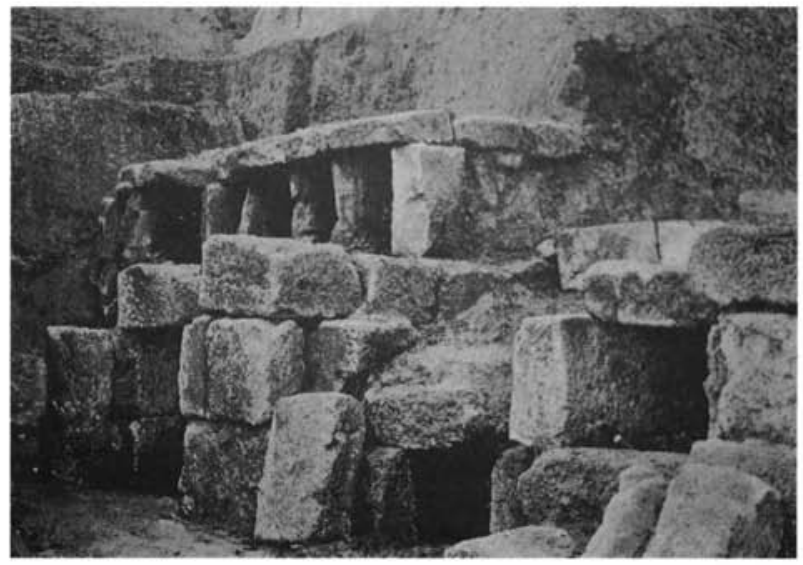

Fig. 4 


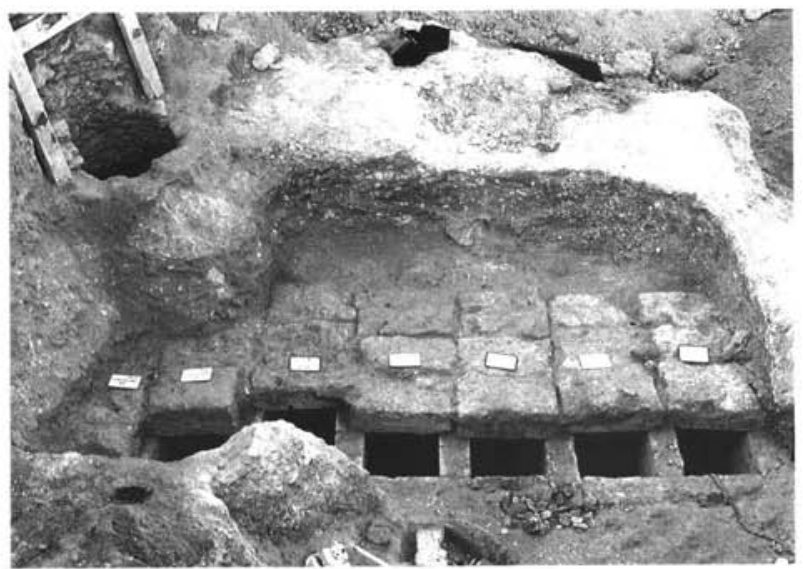

Fig. 5

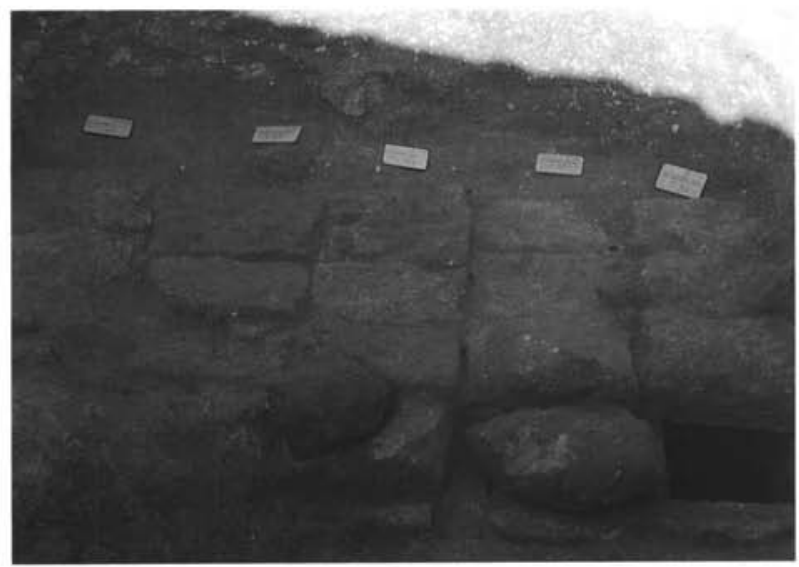

Fig, 6 


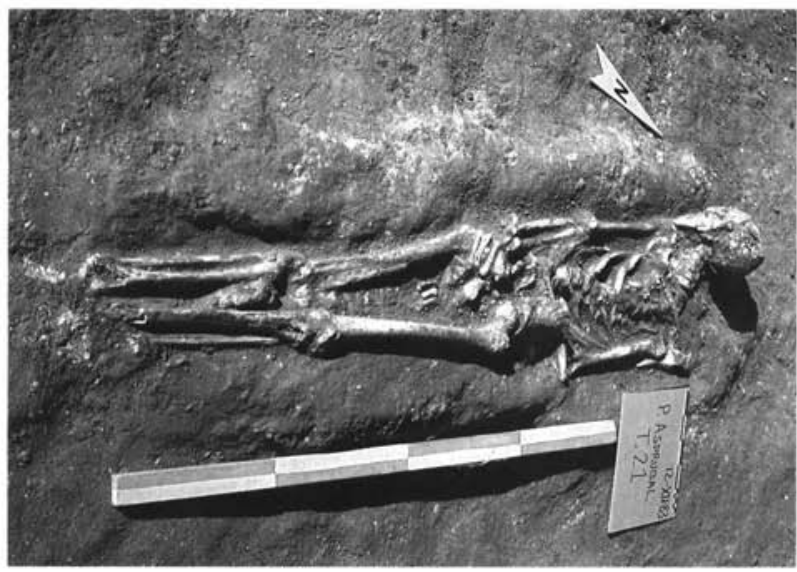

Fig. 7

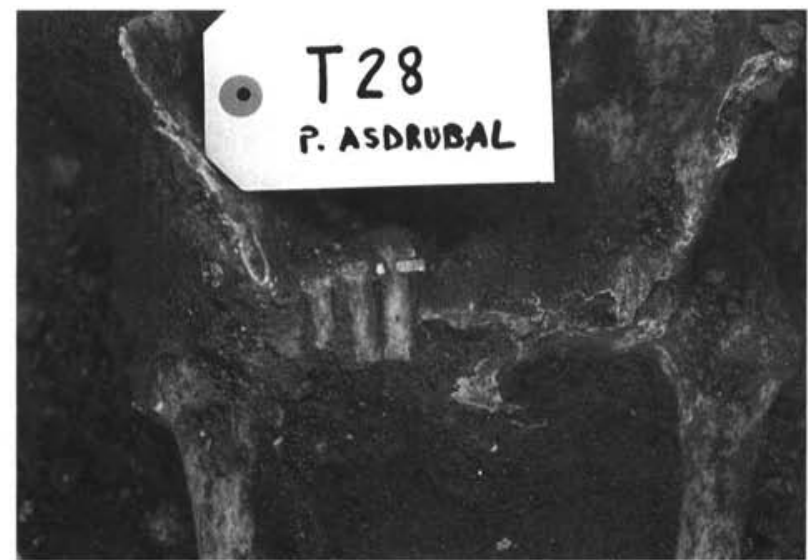

Fig. 8 


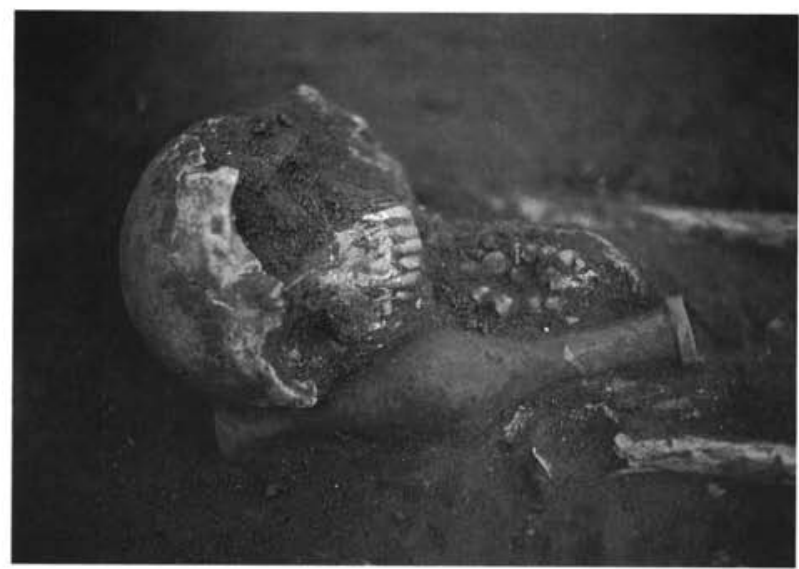

Fig. 9

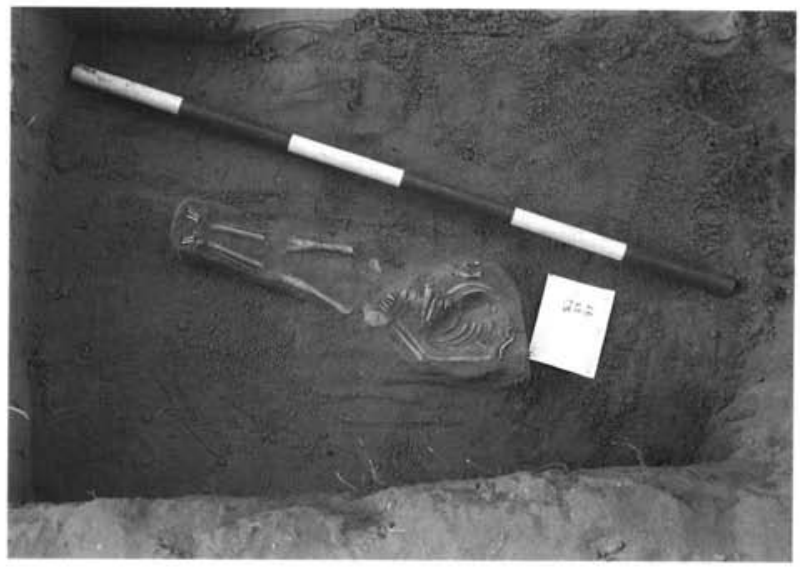

Fig. 10 


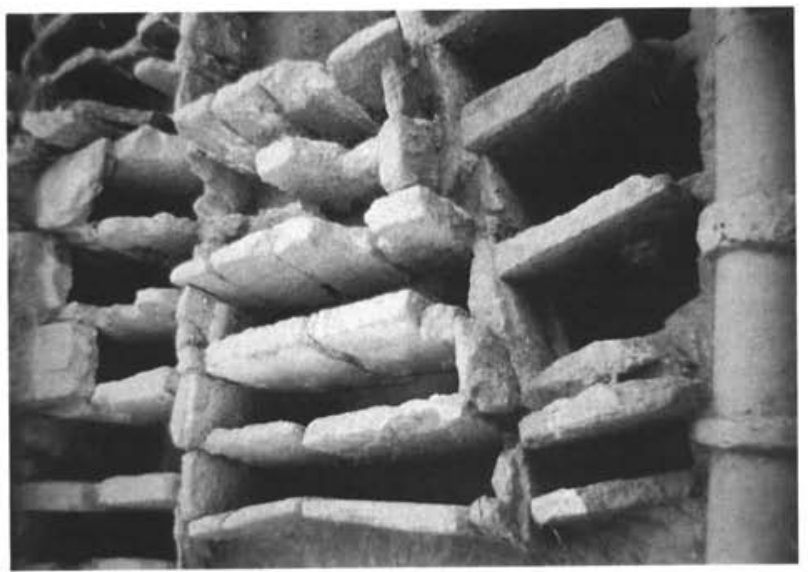

Fig. II

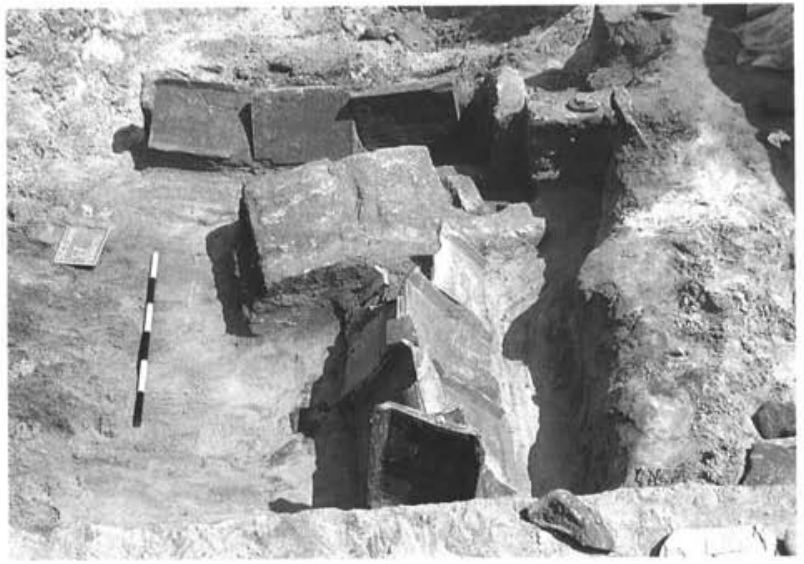

Fig, 12 

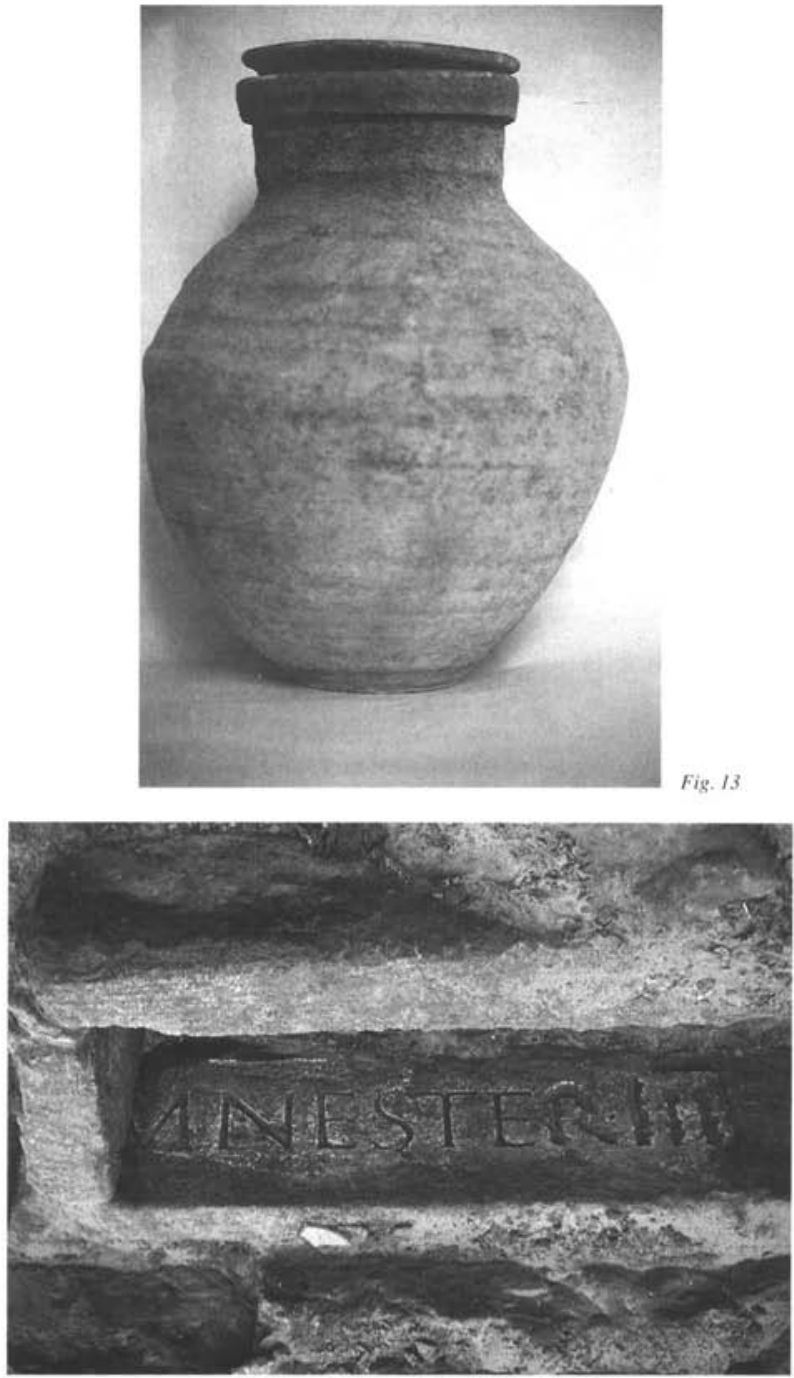

ISSN: 1133-4525 ISSN-e: 2255-3924

Fig. 14 


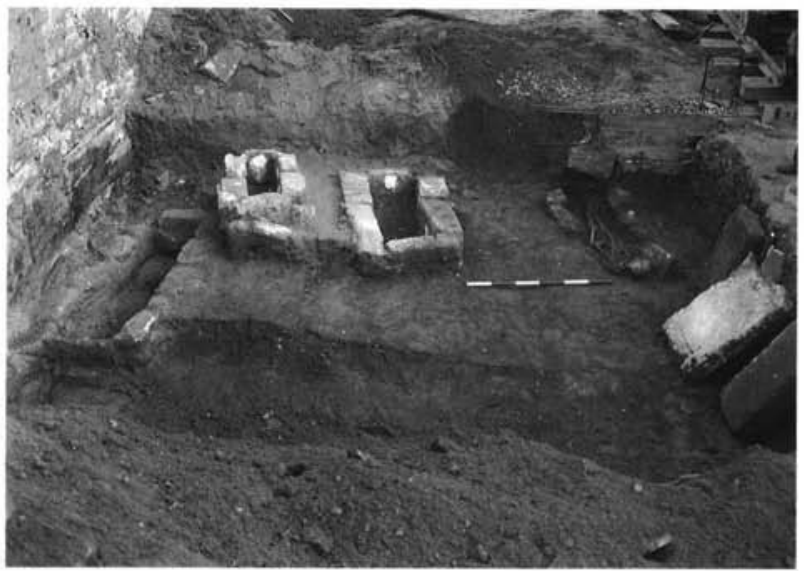

Fig. 15

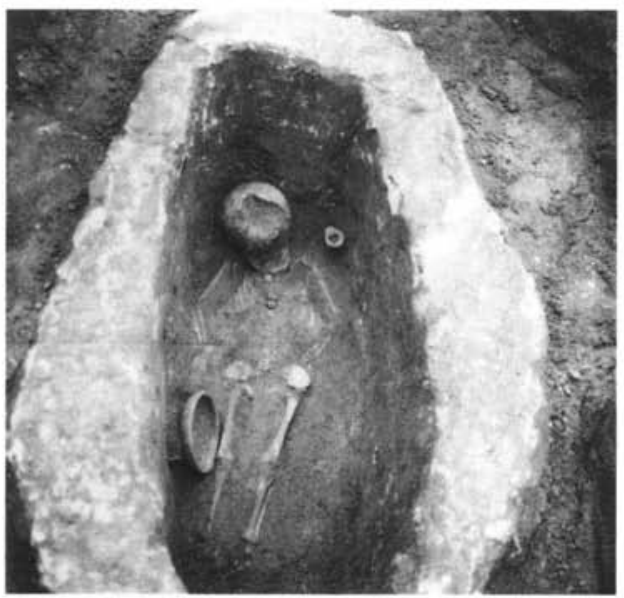

Fig, 16 